\title{
Trends in Gambling Behaviour among NCAA College Student-Ath- letes: A Comparison of 2004, 2008 and 2012 NCAA Survey Data
}

\author{
Rayna M Sansanwal ${ }^{1 *}$, Jeffrey L Derevensky ${ }^{1}$ and Thomas S Paskus ${ }^{2}$ \\ ${ }^{1}$ International Centre for Youth Gambling Problems and High-Risk Behaviors, McGill University, Canada \\ ${ }^{2}$ National Collegiate Athletics Association, Canada
}

*Corresponding author: Rayna Sansanwal, M.A, School/Applied Child Psychology, McGill University, 3724 McTavish Street, Montreal, Quebec, H3A 1Y2, Canada, Tel: 514-398-1391, Fax: 514-398-3401, E-mail: rayna.sansanwal@mail.mcgill.ca

\begin{abstract}
Student-athletes represent a vulnerable subgroup of the college student population with regards to engagement in high-risk behaviours, including gambling. Three large samples of National Collegiate Athletic Association (NCAA) student-athletes in 2004 ( $N=20,587), 2008$ (19,942), and $2012(\mathrm{~N}=22,935)$ were surveyed about their gambling behaviour and attitudes. A cross-sectional study was conducted to gain insight into how the landscape of gambling and attitudes among college student-athletes has changed within the last eight-years in relation to the ongoing expansion of gambling opportunities. Findings revealed gender differences in participation rates of gambling with males consistently engaging in all gambling activities at higher rates than females (57\% of males versus $39 \%$ females in 2012). Despite gender differences, the results suggested that participation rates for all gambling activities has decreased over the eight-year span (57\% of student-athletes in 2012 compared to $70.7 \%$ of student-athletes in 2004), except for past year purchasing of lottery tickets, which increased in 2012 among males. Across sports, gambling participation was notably highest among golfers of both genders. The proportion of student-athletes at-risk or meeting criteria for a gambling problem between 2004 and 2012 has also decreased among males (4\% in 2004 versus $1.9 \%$ in 2012 ) while remaining relatively consistent among females $(<1 \%$ across all years). Taken together, the results suggest that gambling behaviour among NCAA student-athletes is on a downward trend despite the increase in available gambling opportunities.
\end{abstract}

\section{Introduction}

Research has indicated that college students who participate in either club or intercollegiate sports programs are significantly more likely to experience gam- bling-related problems than their non-athletic peers [1]. As such, gambling among college student athletes, has garnered increased public attention among researchers, policy makers, college administrators, and the National Collegiate Athletic Association (NCAA) in the United States. In attempt to preserve the integrity of intercollegiate athletics and the welfare of collegiate athletes, the NCAA membership adopted bylaw 10.3 that prohibits both athletics department staff and student athletes from engaging in gambling activities that relate to intercollegiate or professional sporting events [2]. Despite this bylaw, gambling among college student-athletes remains a multifaceted problem.

\section{Gambling among National Collegiate Athletic Association College Student-Athletes}

The NCAA is responsible for the regulation of student-athletes across member colleges in the U.S., while also governing and enforcing rules that are designed to protect the well-being of student-athletes and maintain integrity and fair play among sports and member institutions [3]. The NCAA has a longstanding history of opposing all forms of legal and illegal gambling on NCAA sports and prohibits student-athletes from engaging in gambling behaviours, specifically in relation to sports wagering, sports pools, and fantasy leagues (money) [3]. In the interests of protecting the integrity of intercollegiate sports and the well-being of student-athletes, the NCAA has conducted multiple comprehensive research programs on many aspects of student life and performance, one of which relates to their concerns re- 
lated to gambling behaviours across all three NCAA divisions in the years 2004, 2008 and 2012, with another data collection scheduled for 2016 . This has allowed the NCAA to gain insight into student-athletes' engagement in gambling activities and in turn, "develop legislation, educational policies and best practices that enhance student-athletes' experiences in college" [3]. Regardless of the rules and regulations surrounding gambling, the NCAA studies on college student-athlete gambling has also allowed researchers to examine trends in gambling behaviour among student-athletes (albeit not longitudinally), including changing gambling preferences, problem disordered gambling, and other gambling-related insights, in relation to the ongoing opportunities to gamble in light of the expansion and changing environment of the gambling industry.

[4] reported on a cross-comparison study of the 2004 ( $N=18,916)$ and $2008(N=17,675)$ NCAA survey data to examine gambling trends among college student-athletes across the four-year span. Their results suggested that yearly participation in gambling behaviours, including lottery tickets, slot machines, horse/dog race wagering, playing the stock market, bingo, and card games (e.g., poker), decreased from 2004 to 2008 with $62.8 \%$ of student-athletes reporting engagement in $2004 \mathrm{com}$ pared to $54.8 \%$ in 2008 . Similarly, $21.9 \%$ of student-athletes reported weekly participation in gambling in 2004, whereas $12.6 \%$ reported gambling on a weekly basis in 2008. Across all sports (played by the athletes), gambling participation was also lower in 2008 compared to 2004 except for student-athlete golfers. However, yearly participation in Internet gambling (6.8\% in 2004 compared to $12.1 \%$ in 2008 ) and sports wagering $(23.5 \%$ in 2004 to $29.3 \%$ in 2008) increased across the four-year span, suggesting that more student-athletes are trying out these forms of gambling. There were also some consistencies in the data. Gender comparisons revealed that males engaged in gambling behaviours significantly more than females in both 2004 and 2008. Additionally, the proportion of student-athletes categorized as at-risk/Probable Pathological Gamblers (PPGs) was consistent from 2004 (2.6\%) to 2008 (2.5\%). Overall, the results suggest that between 2004 and 2008 gambling behaviour among NCAA student-athletes was on a downward trend. This may have been a result in renewed efforts to enforce existing regulations and educational and prevention initiatives.

\section{Contributing Factors to Changing Trends in Gam- bling}

Despite previous trends, there are reasons to suggest that gambling trends among college student-athletes may have changed since 2008 . Social-ecological factors, such as the proliferation of the number of gamblingrelated activities and/or outlets in a specified area, the location of these gambling venues, and the frequency of gambling-related advertisements, influence the availability and in turn, accessibility of gambling opportunities [5]. Additionally, cultural shifts (e.g., more permissive gambling attitudes) can impact how widely accepted gambling is, as a recreational activity. Finally, the expansion of online legal daily and weekly Fantasy sports wagering increased. Changes in these areas may have contributed to changes in gambling trends among NCAA college student-athletes between 2008 and 2012, which has yet to be examined.

\section{Availability and Accessibility}

Geographical, situational and structural factors can enhance access to gambling venues, such as casinos, and increase gambling behaviour related to such activities [6,7]. The American Gaming Association (AGA) conducts yearly detailed analyses of the national and state-by-state economic impact of the commercial casino industry. According to the AGA Survey of Casino Entertainment [8], there were 445 land-based and riverboat casinos operating in 12 U.S. states, 423 Native American tribal casinos operating among 29 U.S. states, and 44 racetrack casinos operating in 12 U.S. states in 2008. As of the end of 2012, the availability of casinos in the U.S. substantially increased; there were 464 land-based and riverboat casinos operating in 17 states, 466 Native American tribal casinos operating in 28 states, and 49 racetrack casinos operating in 14 states [9]. As evident, the gambling industry continued to thrive. There has been an expansion of commercial gaming into new states, as many states have approved commercial casinos in attempt to generate tax revenues, create stable employment opportunities and stimulate economic growth [10]. The increase in the availability of gambling-based venues, such as casinos, allows for greater opportunities for gambling-related behaviour, specifically among college student-athletes [5].

Additionally, the AGA [9] reported that commercial casinos earned US\$32.54 billion in gross gaming revenue in 2008 and this increased to US\$37.34 billion in 2012. Similarly, consumer spending on commercial casino gaming increased from US\$35.62 billion to US\$37.34 billion between 2008 and 2012. The increasing growth rates for gross gambling revenue and consumer spending suggests that the commercial casino industry during this period was continually expanding and general gambling behaviour appears to have increased among the general population. This could potentially include an increase in gambling-related behaviour among the college student population, including college student-athletes.

Emergence of Non-Traditional Forms of Gambling

The expansion of commercial casinos across the U.S. is not the only factor that has contributed to the expansion of the gambling industry between 2008 and 2012. Non-traditional forms of gambling also emerged, thereby, creating greater opportunities to engage in 
gambling behaviour. There are a wide range of government-sponsored and government-regulated forms of gambling that are readily available and easily accessible to the public, including lottery tickets (e.g., Lotto 6/49, Lotto Max, etc.), instant scratch cards (e.g., Monopoly, Bingo, Crossword, etc.), sports betting in certain jurisdictions (e.g., Superbowl, Fantasy Leagues), and Electronic Gambling Machines (EGMs) (e.g., slot machines, Video Lottery Terminals [VLTs], etc.). In Canada, alone, there are currently 30,090 lottery ticket outlets and 96,000 EGMs, while there are more than 12,000 EGMs in the U.S. available to the public $[9,11]$.

The proliferation of the Internet and recent technological advancements, such as personal, portable devices (e.g., tablets) have also led to online and mobile/ smart phone gambling being an easily accessible form of gambling. The availability and accessibility of gambling products via the mobile gaming market presents increased opportunities for vulnerable populations, such as college student-athletes, to engage in gambling behaviours, particularly due to the convenience, lack of supervision, and anonymity associated with online gambling.

\section{Acceptability}

Gambling, as a recreational activity, has proceeded through cycles of being regarded with pervasive acceptance and widespread prohibition [12]. Currently, only a limited number of countries and U.S. states legally prohibit gambling activities; rather, in most jurisdictions, certain forms of gambling are viewed as a socially acceptable form of entertainment. Changing cultural norms has also led to greater accessibility and availability of multiple gambling opportunities.

In several studies examining attitudes towards adolescent gambling, parents [13], teachers [14] and mental health professionals [15] alike perceived gambling to be the least serious issue concerning youth amongst 13 potentially risky adolescent behaviours (e.g., alcohol use, drug use, violence/bullying, unsafe sexual activities, etc.). Likewise, many young adults appear to perceive gambling as a recreational activity that allows for social interaction and self-improvement (e.g., development of critical thinking and communication skills) [16]. Evidently, the overall acceptability of gambling among the general public remains high, which encourages participation in gambling-related activities.

The changing attitudes of school institutions may also contribute to changes in gambling behaviour among student-athletes between the years of 2008 and 2012. The approach school institutions adopt, in relation to risky behaviours, has been shown to significantly influence and impact the attitudes and behaviours of students in terms of their engagement in multiple risky behaviours. For instance, [17] reported that schools who choose to adopt bullying prevention/intervention campaigns are more likely to foster students who promote anti-bullying attitudes and behaviours. As such, given the significant amount of time adolescents and young adults spend at school daily, these institutions can be considered front line in terms of being equipped to influence student's attitudes and in turn, engagement, in multiple high-risk behaviours. [18] analyzed policy information related to gambling and alcohol use in handbooks, Websites, and supplemental material from 119 selected colleges in the U.S. Their results indicated that while all schools had a policy pertaining to alcohol use, only 26 schools (22\%) had some form of a gambling-related policy. Unlike education about substance use, there is currently still no federal mandate requiring schools to educate students about the risks associated with excessive gambling, including academic difficulties, psychosocial problems, financial repercussions, legal issues, and the potential for involvement in other high-risk behaviours [18]. The absence of such a federal mandate outside of the NCAA bylaws combined with limited comprehensive school policies and materials addressing gambling as a highrisk behaviour "leaves an open-door for student-related gambling disorders to emerge unchecked" and can contribute to a general lack of awareness surrounding the dangers associated with gambling among college student-athletes [18].

The mass media also plays a fundamental role in promoting pro-gambling attitudes on both a national and international level. In recent years, there has been a rise in the number of gambling-related shows (e.g., World Series Poker and Las Vegas) and movies (e.g., Runner Runner and Casino Royale) that have appeared across various cable and network genres, including entertainment, sports, and travel [19]. Additionally, participation in gambling activities are commonly endorsed by celebrities; gambling establishments have been sponsored by sports teams; and a range of advertisements promoting casinos and gambling sites have appeared on the television, Internet, radio, and billboards [20]. These cultural values and beliefs, endorsed by the media, are apt to depict gambling in a positive light $[20,21]$. Young adults, therefore, are frequently exposed to messages from a broad range of media that glamorize gambling and transmit the belief that gambling is a pleasurable, exciting, and harmless activity to engage in.

Given the changing landscape of gambling since the NCAA's 2008 study, a follow-up study was conducted in 2012 to examine changes in the patterns and prevalence of gambling behaviours among college student-athletes. The purpose of the current study is to compare results of the 2004, 2008, and 2012 NCAA national surveys. While this represents a cross-sectional study, a comparison of the findings can provide insight into how the landscape of gambling and attitudes among college student-athletes has changed within the last eight-years. Particular attention was paid towards changes in overall 
Table 1: Socio-demographic characteristics of the participants.

\begin{tabular}{|l|l|l|l|}
\hline Variable & $\mathbf{2 0 0 4} \mathbf{( \% )}$ & $\mathbf{2 0 0 8} \mathbf{( \% )}$ & $\mathbf{2 0 1 2} \mathbf{( \% )}$ \\
\hline Gender & \multicolumn{2}{l|}{} \\
\hline Male & 62 & 62 & 57 \\
\hline Female & 38 & 38 & 43 \\
\hline Race/Ethnicity & & & \\
\hline White & 75 & 72 & 77 \\
\hline Black & 15 & 17 & 15 \\
\hline Other & 10 & 11 & 8 \\
\hline Academic Year & & & \\
\hline Freshman & 33 & 35 & 32 \\
\hline Sophomore & 26 & 27 & 27 \\
\hline Junior & 23 & 23 & 25 \\
\hline Senior & 19 & 15 & 16 \\
\hline
\end{tabular}

gambling participation (monthly and yearly), sports wagering, problem gambling rates, and attitudes towards gambling-related behaviours. In addition, due to the ongoing expansion of the online/mobile gambling industry between 2008 and 2012, changes in Internet gambling activities were closely examined.

\section{Method}

\section{Participants}

Data was drawn from surveys administered by the NCAA to U.S. college student-athletes in 2004, 2008, and 2012. The NCAA consists of 1281 colleges and universities in the U.S. Ethics approval was obtained from ethics review committees of respective institutions where the surveys were administered.

A total of 20,587 surveys were administered in 2004; 19,942 were administered in 2008; and 22,935 were administered in 2012. The socio-demographic characteristics of the sample from each year are presented in Table 1.

\section{Survey administration}

A multi-stage cluster sampling design was incorporated in all three studies (2004, 2008, and 2012). Faculty Athletics Representatives (FARs) of all NCAA member colleges were approached to participate. Each school was informed that all members of between one and three teams would be surveyed. Teams were selected based on a stratified random sampling procedure to ensure that all sports in each of the three NCAA divisions would be represented in the total sample. All students and FARs were assured that participation would remain anonymous at the student and institution level. Student-athletes from each team were surveyed at the same time without coaches or other team personnel present. Completed surveys were not handled by FARs. Rather, one student-athlete assumed responsibility for collecting the completed surveys, placing them into a sealed package, and mailing the package to an independent third-party vendor that compiled and entered the data.

As survey responses were submitted anonymously, institutional response rate could not be calculated ab- solutely. The response rate was estimated to be greater than $60 \%$ based upon previous surveys conducted in this manner and the total number of completed surveys received.

\section{Survey content}

The 2004, 2008, and 2012 surveys differed somewhat in content. The 2004 survey collected information on multiple health-risk behaviors (e.g., substance use, sexual activity, and criminal activity) in addition to gambling behavior and demographic information. The 2008 and 2012 survey were significantly modified and streamlined with most items related to health-risk behaviors removed and with a greater focus on gambling behaviors. In all three surveys, student-athletes provided demographic information, details about the college sport they played, and experiences with gambling including extensive questions related to sports wagering and gambling-related problems. All gambling questions referred to participants' behavior during the previous 12 months. Participants were initially categorized as non-gamblers or gamblers based on their responses to the Gambling Activities Questionnaire (GAQ; Gupta \& Derevensky, 1996) portion of the survey which queries frequency of participation for 14 gambling activities over the past 12 months ("daily", "at least once a week", "at least once a month", "less than once a month", and "not at all"). All individuals who reported not gambling in any form in the past year were categorized as non-gamblers. Those who reported having gambling at least once on any of the activities in the previous year (i.e., gamblers) were further divided into three categories based upon their responses to a questionnaire format of the DSM-IV-TR (American Psychiatric Association, 2000) criteria for pathological gambling. This instrument contains 10 items that query the presence of various symptoms and diagnostic criteria associated with pathological gambling including preoccupation with gambling, need to increase better to achieve the same level of excitement (tolerance), loss of control, withdrawal symptoms, escape, chasing of losses, lying to family, illegal activities to pay for gambling, disruptions to family or job, and borrowing money to pay for gambling debts. Standard cut-off scores for problem gambling categorization were used to form three DSM categories of problem gambling. Participants who reported 0-2 symptoms were categorized as Social Gamblers, those who endorsed 3-4 symptoms were categorized as At-risk Gamblers, and those who endorsed 5 or more symptoms were categorized as Probable Pathological Gamblers (PPGs). This questionnaire format has been shown to have strong internal consistency (0.92) and a good agreement rate $(87 \%)$ with another measure of problem gambling severity [22].

\section{Data preparation}

Rigorous data cleaning procedures were implemented to eliminate, as much as possible, invalid data resulting from dubious responses to the surveys. Included 
in these cleaning procedures were a series of validity checks and Item Response Theory techniques to identify questionable patterns of responding. Cases revealing strong evidence of insincere responses (e.g., statistically unlikely combination of responses, inconsistent responding, responses in some portions of the survey that contradict responses elsewhere) were excluded from analyses. These cleaning procedures were applied to the 2004, 2008, and 2012 survey data to enhance comparability. Because these cleaning procedures were applied retroactively to the 2004 survey data, the results reported in this paper are not identical to those previously reported for the same 2004 data (e.g., [23]).

After data cleaning procedures were applied to exclude insincere respondents, a series of steps were applied to account for differences in sampling strategies and survey content between the 2004 and 2008 surveys. These procedures were aimed at making more accurate comparisons across samples. To account for differences in sampling strategies, a filter was applied to both samples such that respondents participating in one of 22 sports (11 men's sports; 11 women's sports) were adequately sampled in each of the three NCAA divisions in 2004, 2008, and 2012. Furthermore, these data were weighted to the NCAA's estimate of 2008 participation rates within the 22 sports to account for differences in sampling proportions within each cohort and scale for the results from both years in relation to current national participation figures.

To account for differences in survey content, an additional set of filters was applied to all samples. Given the present study's main goal of examining changes in problem gambling behaviours and gambling severity rates over the eight-year span, the basis for filtering was implemented to ensure that problem gambling severity rates were comparable. Participants in all samples were categorized as either non-gamblers, social gamblers, at-risk gamblers, or probable pathological gamblers based on responses to the GAQ and DSM-IV-TR questionnaire. However, differences in formatting of the surveys necessitated survey-specific methods of filtering out certain participants with missing data. In the 2004 survey, the GAQ immediately preceded the DSM-IV-TR gambling questions. The DSM-IV-TR questions contain the instruction, "If you have not gambled, bet or wagered in any way during the past 12 months, please skip [this section]". Despite this instruction, some participants who reported gambling on the GAQ skipped the DSM-IV-TR ostensibly because they did not believe themselves to have "gambling problems" suggesting they should be categorized as "social gamblers". Accordingly, the following four guidelines were employed to filter out and categorize respondents: (1) Those who missed the GAQ and DSM-IV-TR were categorized as "missing" and excluded from further analyses (1.5\%); (2) Those who indicated "no gambling" in the past year on the GAQ were categorized as "non-gamblers" whether or not they completed or skipped the DSM-IV-
TR; (3) Those who indicated any gambling participation on the GAQ in the past year but skipped the DSM-IV-TR were categorized as "social gamblers"; and (4) All others who indicated gambling participation on the GAQ and who completed the DSM-IV-TR were categorized according to their scores on the DSM-IV-TR.

Whereas the 2004 survey placed the DSM-IV-TR gambling questions immediately following the GAQ, the 2008 and 2012 survey placed the questions several sections after the GAQ. This gap between the GAQ and DSM-IV-TR in the 2008 survey raises the possibility that some participants might be incorrectly categorized if the 2004 guidelines were applied. For example, a participant might have endorsed gambling in the past year on the GAQ but then stopped completing the survey before reaching the gambling questions. In such a case, the participant would be categorized as a "social gambler" according to 2004 survey guidelines; however, they would be more appropriately filtered out given the possibility that they are an at-risk or pathological gambler. Alternatively, a participant might have endorsed gambling on the GAQ but validly skipped the DSM-IV-TR questions, believing that problem gambling questions do not apply to them. Therefore, the section preceding the DSM-IV-TR was examined to determine if individuals who missed the DSM-IV-TR had done so purposely or had terminated the survey by that point. The following guidelines were employed to filter out and categorize participants in the 2008 sample: (1) Those who missed the GAQ and DSM-IV-TR were categorized as "missing" and excluded from further analyses $(0.4 \%) ;(2)$ Those who missed the section preceding the DSM-IV-TR and did not complete the DSM-IV-TR were categorized as "missing" and excluded from further analysis (8.0\%); (3) Those identified as non-gamblers on the GAQ, did not skip the section preceding the DSM-IV-TR, but skipped the DSM-IV-TR were categorized as "non-gamblers"; (4) Those who indicated any gambling participation on the GAQ in the past year but skipped the DSM-IV-TR, were categorized as "social gamblers"; and (5) All others who indicated any gambling participation on the GAQ and who completed the DSM-IV-TR gambling questions were categorized according to their scores on the DSMIV-TR.

As a result of differences in survey sampling strategies, comparisons are not available across all surveys for each item. While there are 23 official NCAA sports, comparisons are limited to 22 sports (11 men's sports and 11 women's sports) that were adequately sampled in each NCAA division across all three administrations. After applying all data cleaning and filtering procedures, comparative data were available for 19,354 student-athletes from 2004, 19,371 student-athletes from 2008, and 22,935 student-athletes from 2012.

\section{Results}

\section{Gambling activities among student-athletes}


Table 2: Differences in Male Participation in Different Gambling Activities between 2004 and 2012.

\begin{tabular}{|l|l|l|l|l|l|l|}
\hline Gambling activity & \multicolumn{3}{l|}{ Past year gambling (\%) } & \multicolumn{3}{l|}{ Weekly gambling (\%) } \\
\hline & 2004 & 2008 & 2012 & 2004 & 2008 & 2012 \\
\hline Lottery tickets & 36.2 & 31.4 & 35.2 & 11.1 & 9.1 & 11.1 \\
\hline Card games & 46.8 & 45.9 & 27.4 & 20.6 & 14.3 & 6.1 \\
\hline Bet on games of personal skill & 39.7 & 33.1 & 25.4 & 16.3 & 13.0 & 9.9 \\
\hline Horse/dog races & 9.8 & 8.5 & 6.5 & 2.0 & 1.4 & 1.5 \\
\hline Played the stock market & 10.2 & 9.2 & 7.4 & 4.7 & 4.5 & 3.6 \\
\hline Bingo & 6.5 & 6.9 & 5.3 & 0.9 & 1.1 & 1.2 \\
\hline Internet gambling & 6.8 & 12.3 & 7.5 & 2.8 & 4.7 & 1.9 \\
\hline Shot dice & 13.4 & 11.7 & 7.8 & 4.3 & 3.9 & 2.5 \\
\hline Slot machines & 19.8 & 15.1 & 11.9 & 3.6 & 2.0 & 1.8 \\
\hline Sports wagering & 23.5 & 29.5 & 25.7 & 9.6 & 9.6 & 8.3 \\
\hline
\end{tabular}

Male student-athletes: Overall, gambling behaviour among NCAA male student-athletes have decreased over the eight-year span. In $2012,57 \%$ of the males reported engaging in some form of gambling for money within the past year, compared to $65.6 \%$ of males in 2008 and $70.7 \%$ of males in 2004 . This generally lower participation rate among NCAA male student-athletes was observed across most of gambling activities. Differences between the 2004, 2008, and 2012 samples in terms of past year and monthly participation rates with respect to different types of gambling among males are presented in Table 2 . The activity that showed the largest decrease in monthly participation among male student-athletes was playing cards for money $(6.1 \%$ in $2012,14.3 \%$ in 2008 , and $20.6 \%$ in 2004 ). Past year participation rates of playing cards for money were also lowest in 2012. Despite the increase in Internet gambling opportunities over the years, the results showed an increase in yearly participation of casino gaming on the Internet for money among NCAA male student-athletes from $2004(6.8 \%)$ to $2008(12.1 \%)$, but a decrease in 2012 (7.5\%). Monthly participation in Internet casino gaming for money was also lowest in 2012 (1.9\%), compared to 2008 (4.7\%) and 2004 (2.8\%). Additionally, despite the NCAA adopting bylaws that prohibit engagement in gambling activities that relate to intercollegiate or professional sporting events, $25.7 \%$ of male student-athletes reported betting on sports for money in the past year and $8.3 \%$ reported wagering on sports for money at least once a month. For male student-athletes who reported sports wagering, the NFL was the most common pro-sport wagering target $(60.1 \%)$ and basketball tournaments was the most common college sport wagering target (53.1\%). Yearly participation in sports wagering among male student-athletes has slightly increased from 2004 (23.5\%), but has decreased since 2008 (29.5\%). Monthly participation in sports wagering among male student-athletes, however, have remained relatively consistent across the twelve-year span $(9.6 \%$ in 2004 and 2008, and 8.3\% in 2012).

In terms of male student-athletes and sports wagering, monthly sports wagering rates were generally lower in 2012 compared to 2008 and 2004 across all sports, except for golfers (see Figure 1). In 2012, 20.2\% of male golfers reported wagering on sports at least once a month, which increased from $19.6 \%$ in 2008 and $14.2 \%$ on 2004. Male swimmers and track/cross country runners have steadily shown the lowest sports wagering participation rates over the eight-year span, with 3.5\% of male swimmers and $4.4 \%$ of male track/cross country runners in the 2012 survey reporting monthly engagement in sports wagering. Of importance is that male golfers have not only consistently reported the highest rates of sports wagering $(20.2 \%$ versus $7.8 \%$ all other student-athletes reported monthly wagering in 2012), but male golfers are more likely to engage in virtually all types of gambling activities in comparison to other male student-athletes. For example, among male golfers, betting on games involving personal skill, which include on-course bets, was the most frequent wagering activity with $56 \%$ reporting participation in the past year in 2012 , compared to $24 \%$ of all other male student-athletes. Likewise, almost double the number of male golfers reported playing cards for money in the past year in comparison to other student-athletes ( $43 \%$ versus $26.7 \%$, respectively), and $35.4 \%$ of male golfers reported gambling in a casino in the past year, compared to $17.9 \%$ of all other male student-athletes. Thus, gambling and sports wagering among student-athlete golfers remains a concern, as it appears to be moving in the opposite direction of all other athletes.

Female student-athletes: Female student-athletes report engaging in gambling activities at much lower rates than male student-athletes. While overall gambling behaviour among NCAA female student-athletes appear to have decreased from 2004 to 2008, participation rates have remained stagnant from 2008 to 2012; 39\% of females in both the 2012 and 2008 survey reported gambling for money within the past year, compared to $48.9 \%$ of females in 2004 . Among female student-athletes, participation rates across all gambling activities was more consistent. Differences between the 2004, 2008, and 2012 samples of past year and monthly participation rates with respect to different types of gambling among females are presented in Table 3. Past year and monthly participation rates were highest in 2004 for most of activities. Playing cards for money and betting on games involving personal skill showed the largest decline 
25

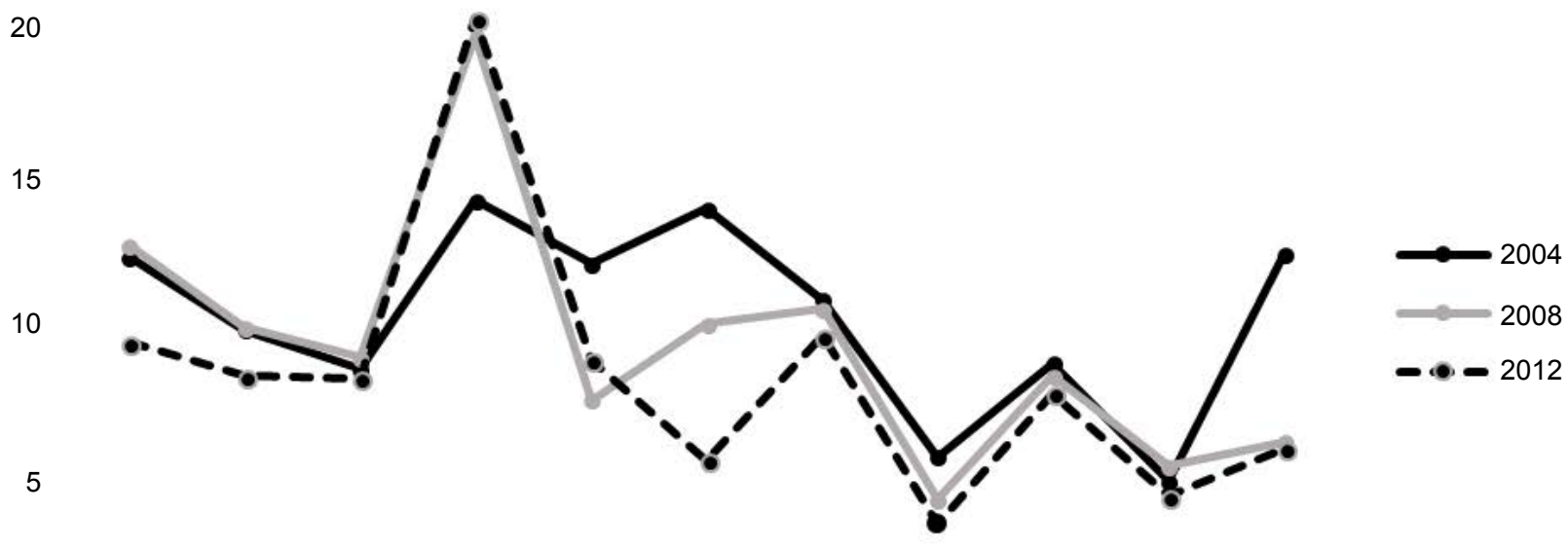

0

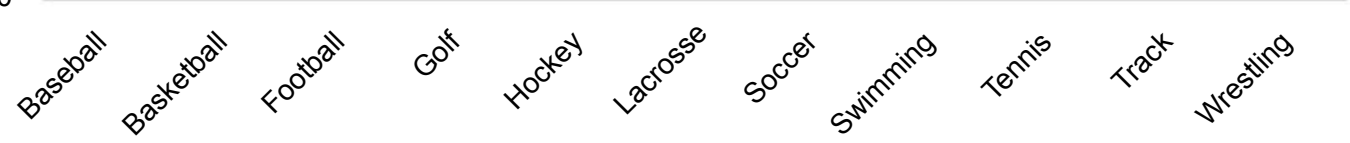

Figure 1: Monthly sports wagering rates among male student-athletes across different sports.

Table 3: Differences in Female Participation in Different Gambling Activities between 2004 and 2012.

\begin{tabular}{|l|l|l|l|l|l|l|}
\hline Gambling activity & \multicolumn{3}{l}{ Past year gambling (\%) } & \multicolumn{3}{l|}{ Weekly gambling (\%) } \\
\hline & 2004 & 2008 & 2012 & 2004 & 2008 & 2012 \\
\hline Lottery tickets & 29.7 & 24.0 & 30.5 & 5.4 & 3.5 & 5.1 \\
\hline Card games & 19.0 & 10.7 & 5.3 & 4.4 & 1.3 & 0.6 \\
\hline Bet on games of personal skill & 14.1 & 7.2 & 4.0 & 3.2 & 1.2 & 0.7 \\
\hline Horse/dog races & 4.8 & 3.2 & 2.8 & 0.4 & 0.1 & 0.2 \\
\hline Played the stock market & 3.5 & 2.1 & 1.1 & 1.3 & 0.6 & 0.4 \\
\hline Bingo & 7.3 & 6.8 & 6.2 & 0.8 & 0.8 & 0.8 \\
\hline Internet gambling & 2.1 & 1.9 & 1.8 & 0.8 & 0.2 & 0.3 \\
\hline Shot dice & 3.5 & 2.2 & 2.0 & 0.7 & 0.3 & 0.3 \\
\hline Slot machines & 14.3 & 9.9 & 8.4 & 1.3 & 0.5 & 0.6 \\
\hline Sports wagering & 6.7 & 6.6 & 5.2 & 1.5 & 0.8 & 0.6 \\
\hline
\end{tabular}

in past year and monthly participation among female student-athletes. There were no differences observed in terms of commercial bingo and casino gambling for money on the Internet among female student-athletes over the twelve-year span. The proportion of female student-athletes who have reported betting on sports for money in the past year and month has also remained consistent, with $5.2 \%$ of female student-athletes reporting wagering on sports in the past year in $2012 ; 6.6 \%$ in 2008; and $6.7 \%$ in 2004. Like males, the NFL (57.7\%) and college basketball tournaments (37.5\%) are the most common sports wagering targets for female student-athletes in the 2012 survey. The one activity that showed an increase in past year participation across the eightyear span were the purchasing of lottery tickets, which increased from $24 \%$ in 2008 to $30 \%$ in 2012 . Apart from the purchasing of lottery tickets, the prevalence of weekly participation in all gambling activities was significantly low for female student-athletes ( $0.8 \%$ or less).
Like male student-athletes, female golfers in 2012 reported the highest rates of past year and monthly gambling (see Figure 2). In 2012, sports wagering participation rates continued to be highest among Division I female golfers (2.1\%), which increased since 2008 (1.7\%) and $2004(0.7 \%)$. The lowest past year and monthly gambling rates continue to be reported by Division I female gymnasts.

Internet gambling \& social media: Technological advancements have changed the way student-athletes can engage in gambling. Among the 2012 cohort, 28.1\% of male student-athletes engaged in some form of simulated gambling activity in the past year, including via videogame consoles $(18.2 \%)$, smartphones $(14.5 \%)$, social media websites (12\%), and Internet gambling websites (10.3\%). In comparison to male student-athletes, $10.2 \%$ of female student-athletes in the 2012 survey reported engaging in some form of simulated gambling activity in the past year. Participation rates among fe- 


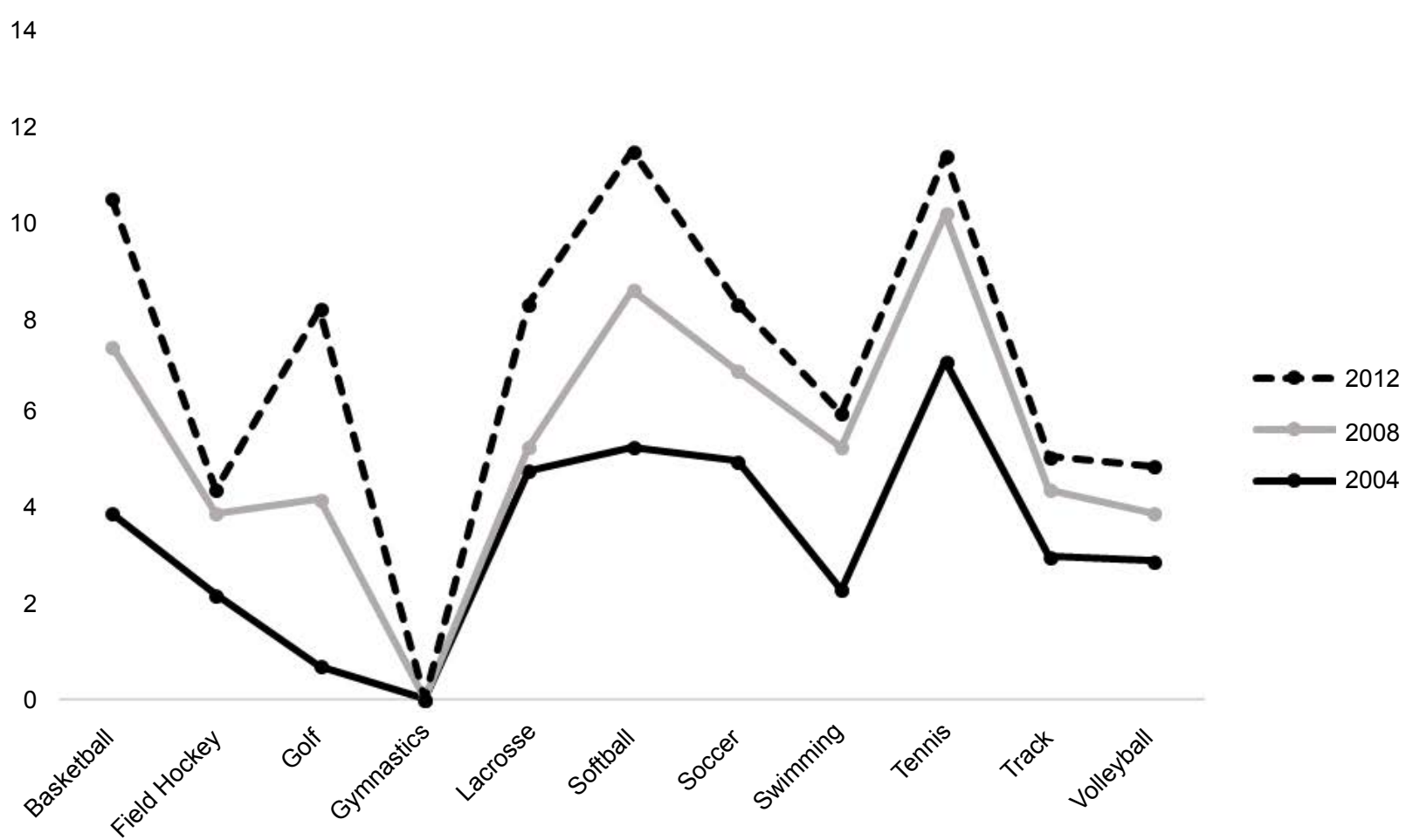

Figure 2: Monthly sports wagering rates of female student-athletes across different sports.

Table 4: Proportion of at-risk gamblers and Probable Pathological Gamblers (PPGS) among male and female student-athletes.

\begin{tabular}{|l|l|l|l|l|l|l|}
\hline DSM Classification & Males (\%) & \multicolumn{3}{l|}{ Females (\%) } \\
\hline & 2004 & 2008 & 2012 & 2004 & 2008 & 2012 \\
\hline Non-gambler & 29.3 & 33.7 & 42.3 & 51.1 & 61.4 & 61.3 \\
\hline Social gambler & 66.7 & 62.5 & 55.8 & 48.6 & 38.2 & 38.6 \\
\hline At-risk gambler & 2.9 & 1.8 & 1.2 & 0.3 & 0.2 & $<0.1$ \\
\hline Probable pathological gambler & 1.1 & 2.0 & 0.7 & $<0.1$ & 0.2 & $<0.1$ \\
\hline
\end{tabular}

male student-athletes were considerably lower with $4.5 \%$ reporting gambling via videogame consoles, $5.4 \%$ via smartphones, $4.2 \%$ via social media websites, and $2.4 \%$ via Internet gambling websites. In the 2012 survey, $33.7 \%$ of male student-athletes, who reported engaging in sports wagering, reported that they place their bets via the Internet or mobile device (e.g., through phone/ text messaging). This has increased from $26.3 \%$ of male student-athletes in the 2008 survey. All other methods used for placing sports betting have remained consistent between 2008 and 2012 among male student-athletes, including betting with friends ( $92.7 \%$ versus $91.5 \%)$, betting with an off-campus bookie ( $7.5 \%$ versus $8.6 \%)$, and betting at casinos/sport books (18.5\% versus $20.9 \%$ ). Data from the 2004 survey regarding placing of bets for sports wagering is unavailable, as this was question was not asked.

Fantasy sports also incorporates the proliferation of the Internet into gambling opportunities. In 2012 and 2008 , approximately $50 \%$ of male-student athletes reported that they participated in a free fantasy league, which increased from $37.6 \%$ in 2004 . In terms of participation in fantasy leagues involving entry fees and prize money, $18.7 \%$ of male student-athletes in the 2012 survey reported engagement, an increase from $17 \%$ in
2008 and $15.5 \%$ in 2004 . Female student-athletes participate in fantasy sports to a lesser extent than male student-athletes. In 2012 and 2008, 8.4\% of female student-athletes reported participation in a free fantasy league, which increased from $5.5 \%$ in 2004 . Among the 2012 cohort, $1.8 \%$ of female student-athletes reportedly participated in fantasy leagues that entailed entry fees and prize money, which slightly decreased from $2.4 \%$ in 2008 and $2.7 \%$ in 2004.

Social media outlets have also been utilized to increase gambling opportunities. Over the eight-year span, there has been a significant increase in the number of student-athletes reporting being contacted by outside sources to share insider information. For example, in the 2004 study, $1.6 \%$ of Division I basketball male student-athletes reported having been contacted by outside gamblers, which increased to $3.5 \%$ in 2008 , and again to $4.6 \%$ in 2012 . However, the percentage of student-athletes who have provided insider information has remained unchanged over the eight-year span. Interestingly, in the 2012 survey, more female than male student-athletes across all divisions reported sharing information on social media websites regarding teammates, training, and preparation for games. For example, $15.4 \%$ of Division I female student-athletes in the 
2012 survey reported sharing this type of information on social media sites, such as Facebook and Twitter, in comparison to $8 \%$ of male student-athletes.

\section{Problem-gambling behaviour}

Overall, the percentage of student-athletes that meet the standard diagnostic criteria for problem gambling has decreased over the twelve-year span (see Table 4). Overall, $42.3 \%$ of male student-athletes were categorized as non-gamblers in 2012, whereas $33.7 \%$ in 2008 and $29.3 \%$ in 2004 were categorized as non-gamblers. In the 2012 survey, $55.8 \%$ of male student-athletes were categorized as social gamblers, compared to $62.5 \%$ in 2008 and $66.7 \%$ in 2004, which also suggests that less male student-athletes have been recreationally engaging in gambling activities over the eight-year span. Overall, $1.2 \%$ of male student-athletes were categorized as at-risk gamblers in 2012 versus $1.8 \%$ in 2008 and $2.9 \%$ in 2004. Likewise, $0.7 \%$ of male student-athletes were categorized as Probable Pathological Gamblers (PPGs) in 2012 versus 2\% in 2008 and $1.1 \%$ in 2004.

With regards to female student-athletes, the proportion of respondents categorized as non-gamblers has increased since 2004 (51.4\%) but has remained consistent between 2008 (61.4\%) to 2012 (61.3\%). A similar trend was found with respect to the proportion of female student-athletes categorized as social gamblers; $38.6 \%$ were categorized as social gamblers in 2012, 38.3\% in 2008 , and $48.6 \%$ in 2004 . Less than $0.1 \%$ of female student-athletes were identified as at-risk gamblers in 2012 versus $0.2 \%$ in 2008 and $0.3 \%$ in 2004. Likewise, less than $0.1 \%$ of female student-athletes were Probable Pathological Gamblers (PPGs) in 2012 versus $0.2 \%$ in 2008 and $<0.1 \%$ in 2004 . Female student-athletes engage in gambling activities at lower rates than males and problem gambling rates among female student-athletes have remained much steadier over the eight-year span in comparison to male student-athletes.

\section{Origin of gambling behaviours}

Male and female student-athletes who reported engaging in gambling behaviours were asked about their age of onset for gambling. In the 2012 survey, the majority of male (59.1\%) and female (57.3\%) student-athletes reported initially gambling for money during highschool. However, a sizable proportion of students begin even before high-school; $32.9 \%$ of male student-athletes and $17.8 \%$ of female student-athletes in the 2012 survey reported engaging in gambling behaviours for the first time before high-school. This has increased from $25.5 \%$ of male and $13.5 \%$ of female student-athletes in the 2008 survey, suggesting that student-athletes are now beginning to gamble at an earlier age than previously reported. Additionally, $8.0 \%$ of males and $24.8 \%$ of female student-athletes in the 2012 survey reported that the first time they gambled for money was while in college, a finding consistent with 2008 survey data, further suggesting that male student-athletes start gambling earlier than their female counterparts. For the 2012 cohort, playing cards for money (47.8\%), sports wagering $(19.6 \%)$, and betting on games of personal skill $(12.3 \%)$ were reported as being the most typical entry point for male student-athletes initial gambling experience. Female student-athletes showed a somewhat different specific entry point than their male counterparts. Lottery/scratch tickets (25.7\%), playing cards for money $(23.5 \%)$, slots $(15.3 \%)$, and sports wagering $(13 \%)$ were the most common activities female student-athletes engaged in as their first gambling experience.

Male and female student-athletes in the 2012 survey reported different companions when engaging in gambling activities. For male student-athletes, they were more likely to gamble with teammates and other student-athletes (33.8\%), as well as other friends or co-workers (33.6\%). Female student-athletes, on the other hand, were more likely to gamble with a significant other or family member (60.6\%) rather than with a teammate (9\%).

\section{Gambling knowledge, education \& attitudes}

Student-athletes were asked about their awareness of NCAA rules and regulations pertaining to gambling and sports wagering. Across the eight-year span, while relatively high, fewer student-athletes in 2012 reported having received information on the NCAA rules concerning gambling. More specifically, $71.5 \%$ of Division I male student-athletes and $75.9 \%$ of Division I female student-athletes reported receiving information on NCAA sports wagering rules in 2012 compared to $76.9 \%$ of male and $83.4 \%$ of female student-athletes in 2008 . Similar trends were also found among Division II and III student-athletes in 2012 and 2008. Of interest is that while fewer student-athletes in 2012 reported having received information on the NCAA rules concerning gambling, a larger proportion of student-athletes in the 2012 cohort compared to the 2008 cohort believe that penalties designed by the NCAA act as an effective deterrent with regards to gambling. In $2012,74.7 \%$ of student-athletes 'agreed' or 'strongly agreed' that the threat of NCAA penalties discourages student-athletes generally from wagering on sports. This is an increase from $63.9 \%$ of student-athletes in the 2008 survey.

In the 2012 survey, a considerable proportion of male and female student-athletes held pro-gambling attitudes. More specifically, among the 2012 cohort, $57 \%$ of male student-athletes and $41 \%$ of female student-athletes believed sports wagering is acceptable so long as the individual is wagering on a sport other than the one in which they participate. This is an increase from $28.5 \%$ of male student-athletes and $9.8 \%$ of female student-athletes in the 2008 cohort who 'agreed' or 'strongly agreed' that wagering on sports other than the one the individual participates in is acceptable. Similarly, $68 \%$ of male and $58 \%$ of female student-athletes in 2012 
perceive sports wagering as a harmless pastime, which largely increased from $53.3 \%$ of male student-athletes and $32.5 \%$ of female-student-athletes in 2008 . Additionally, $59 \%$ of male and $49 \%$ of female student-athletes in 2012 believe gambling can be a means of making a lot of money, which also increased from $51.3 \%$ of male and $35.9 \%$ of female student-athletes in 2008.

\section{Discussion}

Despite the changing landscape of gambling and greater availability and easier accessibility of gambling opportunities over the eight-year span, overall past year and monthly gambling participation rates were lowest in 2012 compared to 2008 and 2004 for college student-athletes, particularly among males. When looking at the changes in gambling severity categorization across the eight-year span, the results indicate an increase in the proportion of student-athletes identified as non-gamblers and a decrease in the proportion of student-athletes categorized as social gamblers. Additionally, when at-risk gamblers and probable pathological gamblers were collapsed into a single group and compared to non-gamblers and social gamblers, there was a significant difference between the 2008 and 2012 cohort with regards to the proportion of student-athletes having a gambling problem or meeting criteria for gambling problems. More specifically, significantly fewer student-athletes in 2012 were experiencing gambling-related problems than student-athletes in 2008. These results present a promising trend in gambling activity among college student-athletes, as participation appears to have decreased over the eight-year span in spite of more enticing forms of gambling and greater availability.

When participation rates in various gambling activities were compared between 2004, 2008, and 2012 , the 2004 sample reported higher rates of past year and monthly gambling participation in almost all activities. Between 2004 and 2008, the only two activities that student-athletes reported higher past year participation rates were Internet gambling and sports wagering. Between 2008 and 2012, yearly and monthly sports wagering participation rates among student-athletes has remained relatively consistent. Given the rapid expansion and increasing popularity of Internet-based gambling since 2008, it was expected that there would be higher rates of Internet gambling reported among student-athletes in 2012. Despite the notion that Internet gambling is a growing concern and poses a significant risk to the student-athlete population given the associated appeal and anonymity, the results indicate that past year and monthly Internet gambling rates among student-athletes had decreased from 2008 to 2012. There are multiple reasons to account for this decrease. [24] interviewed NCAA Division I women ice hockey players about their sources of stress and found that performance expectations, training demands, and academic stressors (e.g., time concerns related to studies), were amongst the primary sources of stress for these student-athletes. Although this study was conducted on NCAA Division I women's hockey players, it is not unreasonable to assume that many NCAA student-athletes, regardless of gender, division or sport, experience similar stressors. As such, given the increasing demands and intensity of intercollegiate sports and academic curriculums over the years, student-athletes may have less time to become or stay involved in Internet gambling or gambling-related activities, in general, without jeopardizing their performance in their sport or academic program. At the same time, career pursuits in sports may also prevent student-athletes from engaging in gambling behaviours (fear of suspension or loss of eligibility), including Internet gambling. Student-athletes are more likely to be under scrutiny from teammates, coaches, scouts/recruiters, etc. As such, detrimental behaviour, like gambling, could hinder the chance for student-athletes to move to the professional level for some. Student-athletes may, therefore, avoid engaging in gambling-related activities, as it has the potential to hamper their professional career. This is interesting to note, as gambling-related behaviour has often been associated with the 'Stress Relief Theory', which suggests that "gambling is a behavioural stress reaction" [25], as gamblers engage in gambling behaviour to avoid anxiety or dysphoric mood by seeking sensation through gambling activities.

Additionally, the NCAA has implemented multiple awareness programs, enforcement groups, and a website (www.dontbetonit.org) designed to provide student-athletes, coaches, and administrators with educational information pertaining to gambling and sports wagering in attempt to decrease the proportion of student-athletes participating in gambling-related activities. These initiatives provide information about NCAA rules and regulations on sports wagering, data on the prevalence of sports wagering among college student-athletes, risks associated with student-athletes engaging in gambling, and resources for student-athletes who may have a gambling-related problem. In 2008, $21.5 \%$ of student-athletes reported receiving information on NCAA gambling rules and consequences from educational materials, including 'Don't Bet on It' websites, booklets, and posters, which is consistent with $24.2 \%$ of student-athletes in 2012. Additionally, in 2012, $47.6 \%$ of student-athletes 'agreed' or 'strongly agreed' that NCAA material, including websites, booklets, and posters, is an effective deterrent of gambling and sports wagering, which increased from approximately 36\% of student-athletes in the 2008 survey. As such, these educational and awareness initiatives implemented by the NCAA may play an important role in discouraging student-athletes from engaging in gambling-related behaviours, including Internet gambling.

Of interest is that while yearly and monthly participation in gambling-related activities, in general, has 
decreased from 2008 to 2012, pro-gambling attitudes have increased over the eight-year span. As such, the decrease in Internet gambling seen in the 2012 survey may be the result of the types of gambling activities student-athlete participants regard as 'Internet gambling'. While overall participation in Internet gambling decreased from 2008 to 2012, sports wagering via the Internet or mobile phone rose from $26.3 \%$ in 2008 to $33.7 \%$ in 2012 . Of interest is that more than half of student-athletes (57\%) in the 2012 perceived sports wagering outside of ones' own sport to be acceptable and not necessarily a form of prohibited gambling. Thus, student-athletes may be selective in what they perceive as being 'Internet gambling' and may not have necessarily reported participating in Internet gambling if they did not believe the activity they were engaging in was a viable form of gambling. For example, student-athletes may have only considered traditional gambling from a computer to constitute Internet online gambling and not necessarily mobile gambling via a smart phone or online Fantasy leagues as being Internet gambling. This was supported by less than one-quarter of male (19.9\%) and female (17.7\%) student-athletes in the 2012 survey who considered participation in a Fantasy league with an entry fee and prize money to be a form of gambling.

This increase in pro-gambling attitudes may be the result of the lack of information that is directly presented to student-athletes. As previously noted, more than half of the student-athletes in the 2012 survey $(68 \%$ of males and $58 \%$ of females) perceived such sports wagering as a harmless pastime, which increased incrementally from the proportion of student-athletes in the 2008 survey who held this belief $(53.3 \%$ of males and $32.5 \%$ of females). As such, a large proportion of student-athletes still appear to be uninformed about the potential risks and consequences associated with certain gambling activities. While the NCAA has increased awareness and educational initiatives aimed at discouraging student-athletes from engaging in gambling activities and sports wagering over the years, the results suggest that less student-athletes are currently being presented with this educational material. Among Division I student-athletes in $2012,71.5 \%$ of males and $75.9 \%$ of females reported that they received information discussing gambling and sports wagering; a decline from $76.9 \%$ of male and $83.4 \%$ of female student-athletes four years earlier. As such, information regarding the risks and consequences of gambling is readily available for student-athletes but is apparently not being directly provided to them. Therefore, to counter pro-gambling attitudes, the NCAA needs to find ways to effectively, efficiently, and directly disseminate this information to student-athletes, rather than student-athletes seeking this information on their own.

One such way that information can be disseminated to student-athletes is through coaches. Protective factors are associated with a reduction in problematic behaviours. In relation to gambling, models for conventional behaviour (e.g., coaches) and involvement in school/clubs (e.g., intercollegiate sports) have been identified as protective factors [26]. While a considerable proportion of student-athletes in both the 2008 and 2012 cohorts reported that NCAA educational material acts as an effective deterrent, most student-athletes (75.8\% in both 2008 and 2012) reported that coaches are the most effective in influencing student-athletes not to engage in gambling-related activities, including sports wagering. In addition, $65.3 \%$ of student-athletes in 2012 believed that their coach could be trusted. While this is the case, only $39.8 \%$ of student-athletes in 2008 and $43.8 \%$ of student-athletes in 2012 reported that coaches would generally be aware of whether teammates are gambling. Given the respected role of coaches and the apparent high standards that student-athletes hold their coaches to, greater efforts can be allocated to training and equipping coaches with the knowledge and resources needed to deter student-athletes from engaging in gambling behaviours, which can play a role in the continual decrease of gambling participation rates among student-athletes. Male student-athletes reported primarily engaging in gambling-related behaviours with teammates. As such, coaches have the potential to be effective and address multiple athletes at the same time at team meetings. Provided that most student-athletes reported beginning their gambling activities in high-school, this may even need to extend to include high-school teachers and staff. However, this continues to present as a challenge given most teachers do not perceive gambling to be a serious issue concerning youth in comparison to high-risk behaviours that adolescents experience [14].

While the number of student-athletes between 2004 and 2012 who have reported wagering on sports has either decreased or remained relatively consistent depending upon the sport played, male golfers remain a concern. In all three divisions, male golfers have the highest prevalence of sports wagering. This is particularly apparent for Division I male golfers, who report wagering on sports nearly twice as much as any of the other Division I men's sports surveyed. In sports, self-efficacy - the judgement of one's ability to use their skills to achieve a desirable outcome - has been identified as having a positive relationship with sport performance [27]. Given the individual nature of golf and reliance on one's own skills, golfer's self-efficacy may account for why sports wagering is highest among golfers and particularly gambling activities involving personal skill [28]. Due to golfer's self-reliance on their own skills, sports wagering (e.g., on-course bets), may also be seen by golfers as a form of competition and as being part of the sport's culture of golf. Thus, golfers may not perceive sports wagering as constituting "gambling" per se and being an activity prohibited by the NCAA. Golfer's participation in sports wagering stemming from this self-reliance on their own skills may also have led to participation in other forms of gambling, which may account for 
why gambling is high across all activities for golfers, not only sports wagering. This is of interest, as student-athletes commonly view gambling as being a team bonding experience, whereas, golfing is typically identified as being more of an individual sport.

\section{Conclusion \& Limitations}

A limitation of the current study is the use of self-report measures where acknowledgement of gambling contravenes NCAA rules and policies. In the 2004, 2008, and 2012 surveys, student-athletes were assured anonymity and that all responses would be kept confidential. However, given that responses to select survey items could be considered a violation of NCAA rules and regulations (e.g., engagement in sports wagering), student-athletes may have been hesitant to reliably report their gambling activities due to fear of loss of eligibility, which may have resulted in student-athletes underreporting their level of engagement in gambling activities. Given the changes in the format and content of the survey over the eight-year span, comparability of responses across the samples is not $100 \%$ perfectly comparable. Additionally, given that this is not a longitudinal study, it is difficult to account for cohort and environmental changes over the eight-year span (e.g., greater educational efforts by the NCAA), which may have influenced the results. Despite the limitations of the current study, the results of this study, the largest study ever reported concerning college student-athletes, suggest an overall decline in gambling rates among student-athletes across the eight-year span, despite the rapid expansion of the gambling industry, easier accessibility, and greater societal acceptance of gambling behaviours.

\section{References}

1. Engwall D, Hunter R, Steinberg M (2004) Gambling and other risk behaviors on university campuses. J Am Coll Health 52: 245-255.

2. National Collegiate Athletic Association (2004) Sports wagering: The threat to collegiate athletics.

3. National Collegiate Athletic Association (2015) Gambling on college sports.

4. Shead NW, Derevensky JL, Paskus TS (2014) Trends in gambling behavior among college student-athletes: A comparison of 2004 and 2008 NCAA survey data. Journal of Gambling Issues 29: 1-21.

5. St-Pierre RA, Walker DM, Derevensky J, Gupta R (2014) How availability and accessibility of gambling venues influence problem gambling: A review of the literature. Gaming Law Review and Economics 18: 150-172.

6. Adams GR, Sullivan AM, Horton KD, Menna R, Guilmette AM (2007) A study of differences in Canadian university students' gambling and proximity to a casino. Journal of Gambling Issues 19: 9-17.

7. Griffiths M (2003) Adolescent gambling: Risk factors and implications for prevention, intervention, and treatment. In: Romer D, Reducing adolescent risk: Toward an integrated approach. Thousand Oaks, CA: Sage, 223-238.

8. American Gaming Association (2009) State of States: The AGA Survey of Casino Entertainment.
9. American Gaming Association (2013) State of States: The AGA Survey of Casino Entertainment.

10. Calcagno PT, Walker DM, Jackson JD (2010) Determinants of the probability and timing of commercial casino legalization in the United States. Public Choice 142: 69-90.

11. Smith $G$ (2014) The nature and scope of gambling in Canada. Addiction 109: 706-710.

12. Derevensky J, Gupta R, Messerlian C, Gillespie M (2004) Youth gambling problems: A need for responsible social policy. Gambling problems in youth: Theoretical and applied perspectives, 231-252.

13. Campbell C, Derevensky J, Meerkamper E, Cutajar J (2011) Parents' perceptions of adolescent gambling: A Canadian national study. Journal of Gambling Issue 25: 36-53.

14. Derevensky JL, St-Pierre RA, Temcheff CE, Gupta R (2014) Teacher awareness and attitudes regarding adolescent risky behaviours: Is adolescent gambling perceived to be a problem? J Gambl Stud 30: 435-451.

15. Temcheff CE, Derevensky JL, St-Pierre RA, Gupta R, Martin I (2014) Beliefs and attitudes of mental health professionals with respect to gambling and other high risk behaviors in schools. International Journal of Mental Health and Addiction 12: 716-729.

16. Calado F, Alexandre J, Griffiths MD (2014) Mom, dad it's only a game! Perceived gambling and gaming behaviors among adolescents and young adults: An exploratory study. International Journal of Mental Health and Addiction 12: 772-794.

17. Salmivalli C (2001) Peer-led intervention campaign against school bullying: who considered it useful, who benefited? Educational Research 43: 263-278.

18. Shaffer HJ, Donato AN, Labrie RA, Kidman RC, Laplante DA (2005) The epidemiology of college alcohol and gambling policies. Harm Reduct J 2: 1.

19. Benston L (2004) Gambling TV backfires hopeful. Las Vegas Sun.

20. Monaghan S, Derevensky J, Sklar A (2008) Impact of gambling advertisements and marketing on children and adolescents: Policy recommendations to minimise harm. Journal of Gambling Issues 22: 252-274.

21. Derevensky J, Sklar A, Gupta R, Messerlian C (2010) An empirical study examining the impact of gambling advertisements on adolescent gambling attitudes and behaviors. International Journal of Mental Health and Addiction 8: 21-34.

22. Stinchfield R, Govoni R, Frisch GR (2005) DSM-IV diagnostic criteria for pathological gambling: Reliability, validity and classification accuracy. Am J Addict 14: 73-82.

23. Ellenbogen S, Jacobs D, Derevensky J, Gupta R, Paskus T (2008) Gambling behaviour among college student-athletes. Journal of Applied Sports Psychology 20: 349-362.

24. Heller TL, Bloom GA, Neil GI, Salmela JH (2003) Sources of stress in NCAA Division 1 women ice hockey players (Unpublished Doctoral Dissertation). Montreal, QC: McGill University.

25. Blaszczynski A, McConaghy N (1989) Anxiety and/or depression in the pathogenesis of addictive gambling. Int $\mathrm{J}$ Addict 24: 337-350.

26. Dickson L, Derevensky JL, Gupta R (2008) Youth gambling problems: Examining risk and protective factors. International Gambling Studies 8: 25-47.

27. Moritz SE, Feltz DL, Fahrbach KR, Mack DE (2000) The relation of self-efficacy measures to sport performance: a meta-analytic review. Res Q Exerc Sport 71: 280-294.

28. Ariyabuddhiphongs V, Promsakha $\mathrm{Na}$ Sakolnakorn C (2014) Peer pressure and thai amateur golfers' gambling on their games: the mediating effect of golf self-efficacy. $J$ Gambl Stud 30: 685-696. 